\title{
Polymorphism in IncRNA AC008392.I and its interaction with smoking on the risk of lung cancer in a Chinese population
}

This article was published in the following Dove Press journal: Cancer Management and Research

\author{
Xiaoting $L^{1,2}$ \\ Zhigang Cui ${ }^{3}$ \\ Hang $L i^{1,2}$ \\ Juan $\mathrm{Li}^{1,2}$ \\ Zitai Yang ${ }^{1,2}$ \\ Yanhong $\mathrm{Bi}^{1,2}$ \\ Min Gao ${ }^{1,2}$ \\ Baosen Zhou ${ }^{1,2}$ \\ Zhihua Yin ${ }^{1,2}$ \\ 'Department of Epidemiology, School \\ of Public Health, China Medical \\ University, Shenyang, II0I22, People's \\ Republic of China; ' Key Laboratory \\ of Cancer Etiology and Intervention, \\ University of Liaoning Province, \\ Shenyang, I I 0 I 22, People's Republic \\ of China; ${ }^{3}$ chool of Nursing, China \\ Medical University, Shenyang, II0I22, \\ People's Republic of China
}

Correspondence: Zhihua Yin

Department of Epidemiology, School of Public Health, China Medical University, Number 77 Puhe Road, Shenyang North New Area, Shenyang, II0I22, People's Republic of China

$\mathrm{Tel}+86$ I89 009| 0228

Email zhyin@cmu.edu.cn
Purpose: To evaluate the association between rs7248320 in lncRNA AC008392.1 and the risk of lung cancer, this case-control study was carried out in a Chinese population. This study also evaluated the gene-environment interaction between rs7248320 and exposure to smoking status on the risk of lung cancer.

Patients and methods: We conducted a hospital-based case-control study including 512 lung cancer cases and 588 healthy controls. The association between rs 7248320 and the risk of lung cancer was analyzed, and the gene-environment interaction was estimated on an additive scale. Results: The variant genotype of rs 7248320 was significantly related to the risk of non-small-cell lung cancer (NSCLC). Individuals carrying homozygous GG genotype had decreased risk of NSCLC, compared with individuals carrying the homozygous wild AA genotype/heterozygote GA genotype (adjusted odds ratio $[\mathrm{OR}]=0.653,95 \%$ confidence interval $[\mathrm{CI}]=0.442-0.966$, $P=0.033$ ). Moreover, in the subgroup of ages, there were statistically significant associations between rs 7248320 and the risk of lung cancer and NSCLC in the population over 60 years of age. Compared with individuals carrying genotypes AA/GA, individuals with genotype GG had the lower risk of lung cancer and NSCLC (adjusted ORs were 0.579 and $0.433,95 \%$ CIs were $0.338-0.994$ and $0.231-0.811, P$-values were 0.048 and 0.009 , respectively). Compared with homozygote AA, the homozygote GG was associated with a decreased risk in NSCLC ( $\mathrm{OR}=0.456,95 \% \mathrm{CI}=0.235-0.887, P=0.021$ ). There were no statistically significant results in gene-environment interactions on an additive scale.

Conclusion: These findings suggest that lncRNA AC008392.1 rs7248320 may be involved in genetic susceptibility to NSCLC in a Chinese population.

Keywords: lung cancer, single-nucleotide polymorphism, lncRNA, susceptibility, CARD8

\section{Introduction}

Lung cancer, remaining an important public health burden worldwide, was a leading cause of cancer-related morbidity and mortality around the world, especially in China. ${ }^{1,2}$ Data in the International Agency for Research on Cancer by Region (2008-2012) indicated that lung cancer was one of the most common form of malignancy affecting human worldwide.

The increasing number of studies have shown that the tumorigenesis of lung cancer is a complex process involving multiple genetic, environmental factors, and the interaction of them. ${ }^{3,4}$ The development of high-throughput DNA sequencing and array projects, including the Encyclopedia of DNA Elements, ${ }^{5} 29$ Mammals Project, ${ }^{6}$ and Health Roadmap Epigenomics Project, ${ }^{7}$ leads to the identification of non-coding RNAs 
(ncRNAs). ${ }^{8}$ Of the two types of human genome sequences, ncRNAs and protein coding RNAs, $\sim 99 \%$ are ncRNAs, which also play an important role in regulating transcription. ${ }^{9,10}$ As the regulators of protein coding genes, ncRNAs include small nuclear RNA, microRNA (miRNA), small interfering RNA, long non-coding RNA (lncRNA), and so on. ${ }^{11}$ In the past years, most studies focused on miRNAs that influenced various cellular processes including inhibiting cell proliferation, inducing cell apoptosis, and so on. ${ }^{12-15}$

In human genome, lncRNAs are vital parts of "dark matter." As the vast majority of ncRNAs, lncRNAs are becoming the new focus of science studies. ${ }^{16-18}$ The length of lncRNAs are $>200$ nucleotides, ${ }^{19}$ and $\operatorname{lncRNAs}$ can influence the pathologic processes, comprising disease and carcinogenesis..$^{8,20-22}$ Furthermore, due to the attention on lncRNAs, many studies found that lncRNAs played important roles in cellular processes such as cell growth, ${ }^{23}$ cell apoptosis, ${ }^{24}$ cell differentiation, ${ }^{25}$ cell proliferation, ${ }^{26}$ cell metastasis, cancer progression, and autophagy. ${ }^{27,28}$ Accumulated evidence has shown that the single-nucleotide polymorphisms (SNPs) are the most common genetic variants in miRNAs and IncRNAs. ${ }^{12,29}$

As a member of caspase recruitment domain family, caspase recruitment domain family member 8 (CARD8), which is involved in the interleukin-1 $\beta$ (IL-1 $\beta$ ) processing pathway, ${ }^{30,31}$ protein-protein interaction modules, cell apoptosis, ${ }^{32}$ the suppressor of caspase-1, and the activation of nuclear factor kappa-B $(\mathrm{NF}-\kappa \mathrm{B}) .{ }^{33} \mathrm{NF}-\kappa \mathrm{B}$ is a key regulator for gene transcription and tumor genesis. ${ }^{34}$ And the activation of NF-kB was effectively suppressed by CARD8 through inflammatory mediators. ${ }^{35}$ The defects of apoptosis are seen in many forms of cancer. ${ }^{36} \mathrm{CARD} 8$ has influence on cancers by decreasing the cell apoptosis..$^{30,37}$ The expression of CARD8 was related with poor prognosis in colon cancer cases and the high expression level of CARD8 could reduce the survival time of colon cancer cases. ${ }^{32,37,38}$ The overexpression of CARD8 was found in non-small-cell lung cancer (NSCLC) cells rather than small-cell lung cancer (SCLC). ${ }^{39}$ Recently, a pilot study has shown that homozygous mutations of CARD8 might conduce to the higher susceptibility of cancers including lung cancer. ${ }^{39,40}$

LncRNA AC008392.1, located in the upstream region of CARD8 in the long arm of the nineteenth chromosome, is one of the recently identified lncRNAs. The expression of lncRNA AC008392.1 is found in many cell lines including human B lymphocyte and human cervical cancer cells. ${ }^{41}$ Some studies have demonstrated that rs7248320 in AC008392.1 may represent the expression quantitative trait loci (eQTL) for
CARD8. Hence, it may change the expression of CARD8. ${ }^{41,42}$ Yin et al reported that the variant genotype of rs7248320GG increased the risks of hepatocellular carcinoma (HCC) and cervical cancer. ${ }^{41}$ Therefore, rs7248320 may relate with the risks of cancers by influencing the interaction between lncRNA AC008392.1 and CARD8. And then, we assumed that the SNP rs 7248320 may alter the risk of lung cancer by influencing the expression of CARD8. To evaluate the role of rs7248320 in lncRNA AC008392.1 on the susceptibility of lung cancer, we carried out a case-control study including 512 lung cancer patients and 588 controls.

\section{Materials and methods Study subjects}

This study is a hospital-based case-control study, which is carried out in Shenyang City, northeast China. We recruited 512 lung cancer patients and 588 healthy controls. The inclusion criteria for cases were: 1) newly confirmed as lung cancer patients, 2) no treatment (both chemotherapy and radiotherapy), and 3 ) capability to have a $1.5 \mathrm{~h}$ interview. The cases were without any previous cancer or metastatic cancer. The inclusion criteria for healthy controls were: 1) without history of cancer, 2) selected from the same hospital during the same period, and 3 ) matched to case subjects by age $( \pm 5$ years). Participants with unrelated kinship were Chinese Han population. This case-control study was approved by the Institutional Review Board of China Medical University, and each participant signed an informed consent. For each participant, an interview was scheduled to get the information on demographic data and environmental exposure status when she or he was admitted to hospital, and all the participants donated $\sim 10 \mathrm{~mL}$ of venous blood sample for SNP detection. An individual who smoked $<100$ cigarettes in his lifetime was defined as non-smoker, otherwise was categorized as smoker. The minor allele frequency (MAF) of our selected SNP was $>5 \%$ in Chinese population. Genomic DNA samples were extracted from venous blood by phenol-chloroform method. An Applied Biosystems 7500 FAST Real-Time PCR System using Taqman ${ }^{\circledR}$ allelic discrimination was used for SNP genotyping. Negative control was included in each genotyping. More than $10 \%$ of samples which were tested twice by two persons were randomly selected, and the results showed that the concordance rate was $100 \%$.

\section{Statistical analysis}

Student's $t$-test and $\chi^{2}$ test were respectively used to calculate the differences of demographic variables and genotype distribution of SNP rs7248320 in continuous and categorical 
variables between the case group and the control group. The goodness-of-fit $\chi^{2}$ test was performed to analyze the HardyWeinberg equilibrium (HWE) of the SNP rs7248320. Unconditional logistic regression analyses calculated the odds ratios (ORs) and their 95\% confidence intervals (CIs) to estimate the associations between SNP rs 7248320 and the risk of lung cancer and NSCLC. Statistical significance was set as $P<0.05$, and all tests were two-sided, and all of the statistical analyses were performed by using SPSS (version 20.0).

\section{Results}

This ongoing epidemiologic study included 512 cases of lung cancer and 588 controls of healthy population, whose characteristics are described in Table 1. There were no statistically significant differences in the proportion of age and sex status between the lung cancer case group (mean age 58.04 \pm 11.626 years and $66.8 \%$ females) and the control group (mean age $56.52 \pm 15.781$ years and $68.20 \%$ females). However, the distribution of smoking status was significantly higher in lung cancer cases than in healthy controls $(P=0.006)$. In addition, tumor node metastasis (TNM) stage (17.8\% of TNM stage I and II, $40.4 \%$ of TNM stage III, $12.5 \%$ of TNM stage IV, and $29.3 \%$ were missing) and pathological type (50.4\% of lung adenocarcinoma $[(\mathrm{AD}], 21.5 \%$ of lung squamous cell carcinoma [SQ], $23.0 \%$ of small cell lung cancer [SCC], and $5.1 \%$ of others) of the cases were listed. The frequency of genotype was expected under HWE in controls $(P=0.11332>0.05)$. Table 2 shows the observed allele and genotype frequency distribution for rs 7248320 SNP in case subjects and control

Table I Distribution of demographic variables in lung cancer cases and controls

\begin{tabular}{|c|c|c|c|}
\hline Variables & Cases $(\mathrm{N}=5 \mid 2)$ & Controls $(\mathrm{N}=588)$ & $P$-value \\
\hline Age (mean $\pm S D)$ & $58.04 \pm 11.626$ & $56.52 \pm|5.78|$ & 0.071 \\
\hline Gender & & & 0.621 \\
\hline Female & $342(66.8 \%)$ & $40 \mathrm{I}(68.20 \%)$ & \\
\hline Male & 170 (33.2\%) & 187 (31.8\%) & \\
\hline Smoking status & & & 0.006 \\
\hline Ever & 144 (28.1\%) & $|2|(20.6 \%)$ & \\
\hline Never & 368 (71.9\%) & 467 (79.4\%) & \\
\hline \multicolumn{4}{|l|}{ TNM stage } \\
\hline I, II & 91 (I7.8\%) & & \\
\hline III & 207 (40.4\%) & & \\
\hline IV & $64(12.5 \%)$ & & \\
\hline Other & $150(29.3 \%)$ & & \\
\hline \multicolumn{4}{|l|}{ Pathological type } \\
\hline$A D$ & 258 (50.4\%) & & \\
\hline SQ & $110(21.5 \%)$ & & \\
\hline $\mathrm{SCC}$ & $118(23.0 \%)$ & & \\
\hline Other & $26(5.1 \%)$ & & \\
\hline
\end{tabular}

Abbreviations: AD, lung adenocarcinoma; SCC, small-cell lung cancer; SQ, lung squamous cell carcinoma.

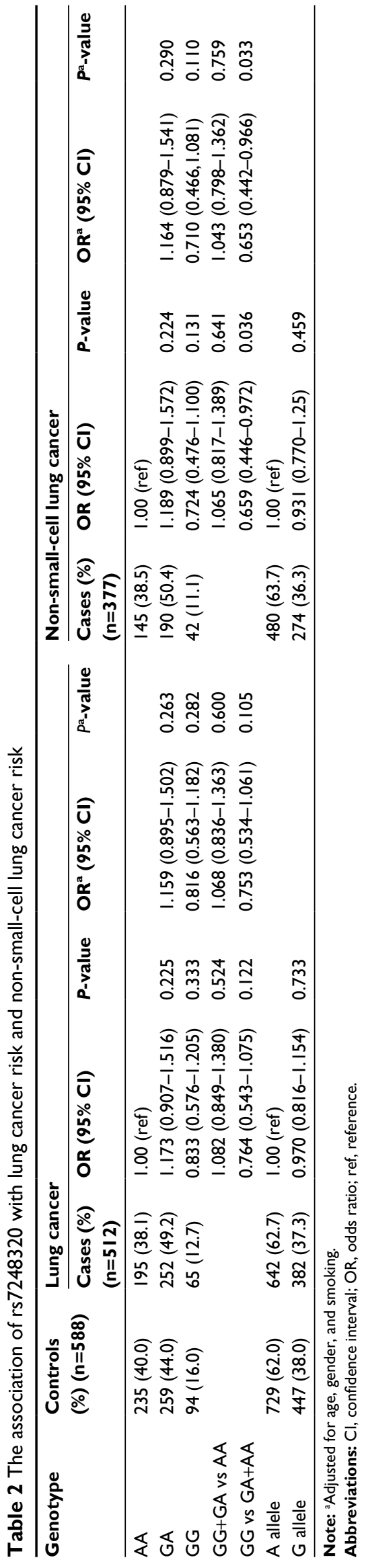


subjects. The associations between the SNP rs7248320 and risk of lung cancer and NSCLC are also shown in Table 2. There were no statistically significant associations between rs7248320 polymorphism and risk of lung cancer in this present study in four models (GA vs AA: OR $=1.159,95 \%$ $\mathrm{CI}=0.895-1.502, P=0.263$; $\mathrm{GG}$ vs $\mathrm{AA}: \mathrm{OR}=0.816,95 \% \mathrm{CI}$ $=0.536-1.182, P=0.282 ; \mathrm{GG}+\mathrm{GA}$ vs $\mathrm{AA}: \mathrm{OR}=1.068,95 \% \mathrm{CI}$ $=0.836-1.363, P=0.600 ; \mathrm{GG}$ vs GA+AA: OR $=0.753,95 \% \mathrm{CI}$ $=0.534-1.061, P=0.105$; adjusted for age, sex, and smoking status). We further performed subgroup analysis stratified by pathological type of lung cancer to investigate whether rs7248320 relate with the risk of NSCLC, SQ, and AD. We found that individuals carrying homozygous GG genotype had decreased risk of NSCLC by 0.653 -fold (adjusted OR $=0.653,95 \% \mathrm{CI}=0.442-0.966, P=0.033$ ) compared with individuals carrying the homozygous wild AA genotype/the heterozygote GA genotype. The associations of rs 7248320 with SQ and AD are listed in Table 3. We failed to find the statistically significant association between rs7248320 and SQ. The same results were also found in AD group. Table 4 shows the associations between rs 7248320 and lung cancer and NSCLC in female and male, respectively. In the subgroup of sex, there were no statistically significant associations between rs7248320 polymorphism and overall risk of lung cancer and NSCLC in female. The same results existed in male. We performed a subgroup-stratified analysis by smoking status, but we failed to find any statistically significant associations, and the results were shown in Table 5. In the subgroup analysis of ages, we found the significant association between rs7248320 and lung cancer risk in the second group ( $>60$ years). Compared with the individuals carrying genotypes AA/GA, individuals carrying genotype GG had the lower lung cancer risk by 0.579 -fold (adjusted 95\% CI $=0.338-0.994, P=0.048)$. The same results existed in NSCLC in Table 6. Compared with homozygote AA, the homozygote GG was associated with a decreased risk in NSCLC (adjusted OR $=0.456,95 \% \mathrm{CI}=0.235-0.887$, $P=0.021$ ). Individuals with $\mathrm{GG}$ genotype also had a reduced susceptibility of NSCLC compared with homozygote AA and genotype GA (adjusted $\mathrm{OR}=0.433,95 \% \mathrm{CI}=0.231-0.811$, $P=0.009$ ). In further analysis, we wanted to know about the interaction between the SNP rs7248320 and smoking exposure on the susceptibility of lung cancer, NSCLC, AD, and SQ (Tables 7-9). Compared to individuals with both GA/ AA genotypes and exposure to smoking status, individuals with homozygous GG genotype and never smoking status had the increased risk of lung cancer and NSCLC (adjusted ORs were 2.319 and $1.963,95 \%$ CIs were $1.416-3.798$ and

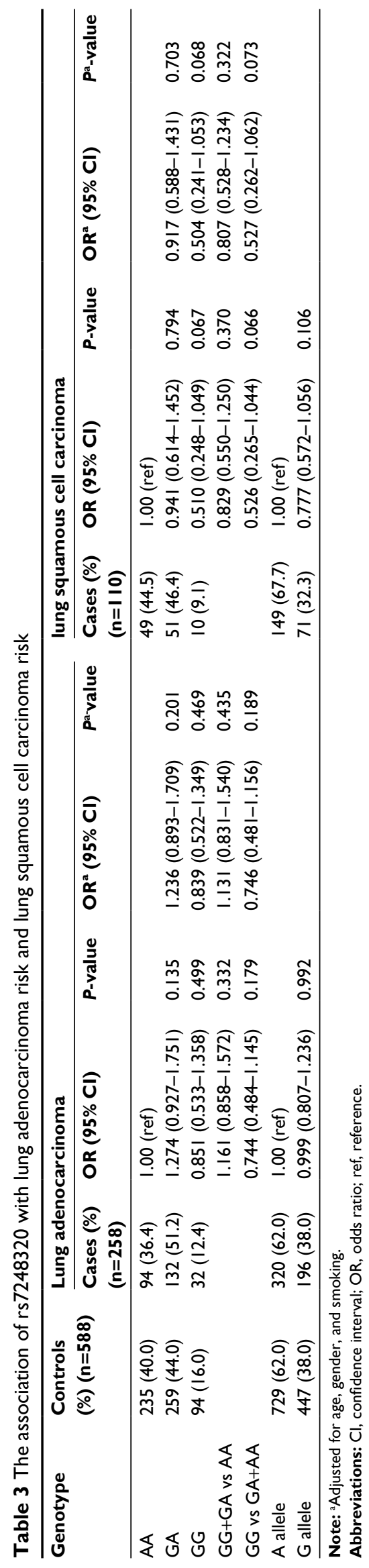




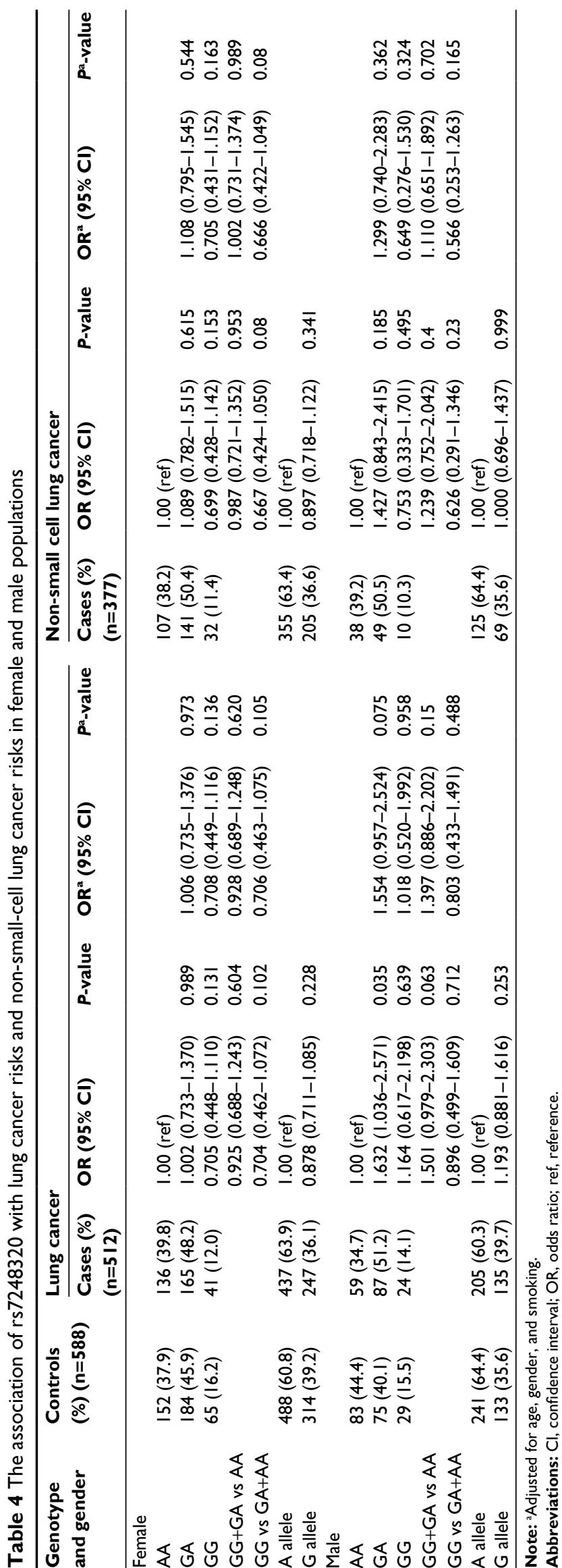

1.134-3.399, $P$-values were 0.001 and 0.016 , respectively). Similarly, the same results existed in SQ (adjusted OR $=4.846,95 \% \mathrm{CI}=1.892-12.416, P=0.001)$. However, the quantitative analyses suggested that the interactions between rs7248320 in lncRNA AC008392.1 and exposure to smoking on risks of lung cancer, NSCLC, AD, and SQ were not significant on an additive scale (Table 9). In additive model interaction, three measures (relative excess risk due to interaction and the attributable proportion due to interaction, and the synergy index) with their $95 \% \mathrm{CI}$ were used to show the relationship, and the criterion of these three measures was just as in our previous study. ${ }^{43}$

\section{Discussion}

During the period from 2008 to 2012, the Cancer Registry of the Center of China counted 13,155 new cases of pulmonary diseases (trachea, bronchus, and lung cancer). The crude incidence rate of cancer was 44.9 per $100,000 \mathrm{~s}$ and the age-standardized incidence rate (ASR) world was 52.7 per 100,000 s for men during the study period. Then, there were 28.2 new cancer cases per 100,000s, and the ASR world was 28.4 per 100,000 s during the study period. Moreover, lung cancer is one of the cancers that is most difficult to diagnose at the early stage, and most lung cancer cases are too late to be treated. ${ }^{8,28}$ In recent years, IncRNAs were identified by progressive science and technology; the functions of lncRNAs are becoming the hotspot in different diseases including tumor. The dysregulations of lncRNAs may influence the level of gene expression, thus potentially playing an essential role on susceptibility to lung cancer. Many studies have shown that lncRNAs were deregulated in lung cancer, such as MALAT1 (NEAT2), ${ }^{44,45}$ HOTAIR, ${ }^{46}$ SOX2-OT, ${ }^{47}$ and H19. ${ }^{48}$ MALAT1 could be associated with prognostic parameter for poor survival ${ }^{49}$ and cell migration ${ }^{50}$ in lung cancer cases. Compared with normal lung tissue, the expression of HOTAIR was higher in lung cancer tissues. ${ }^{51}$ SOX2-OT could play a vital role in regulating cell proliferation and become a novel indicator for lung cancer. ${ }^{52}$

LncRNA AC008392.1, located in the upstream region of CARD8, may affect the normal expression of CARD8. ${ }^{41}$ CARD8 may influence the tumor biology by inhibiting cell apoptosis $\mathrm{s}^{32,53}$ and involving the NF-kB pathway. ${ }^{54} \mathrm{In} \mathrm{dbSNP}$ database, the MAF of rs 7248320 in the Chinese population was 0.402 (MAF >0.05). The relationship between rs 7248320 and other cancers risk have been reported in the past years. Yin et $\mathrm{al}^{41}$ reported that the variant genotype of GG increased the risk of HCC (adjusted OR $=1.28,95 \% \mathrm{CI}$ $=1.03-1.61, P=0.028)$ as compared with individuals with 


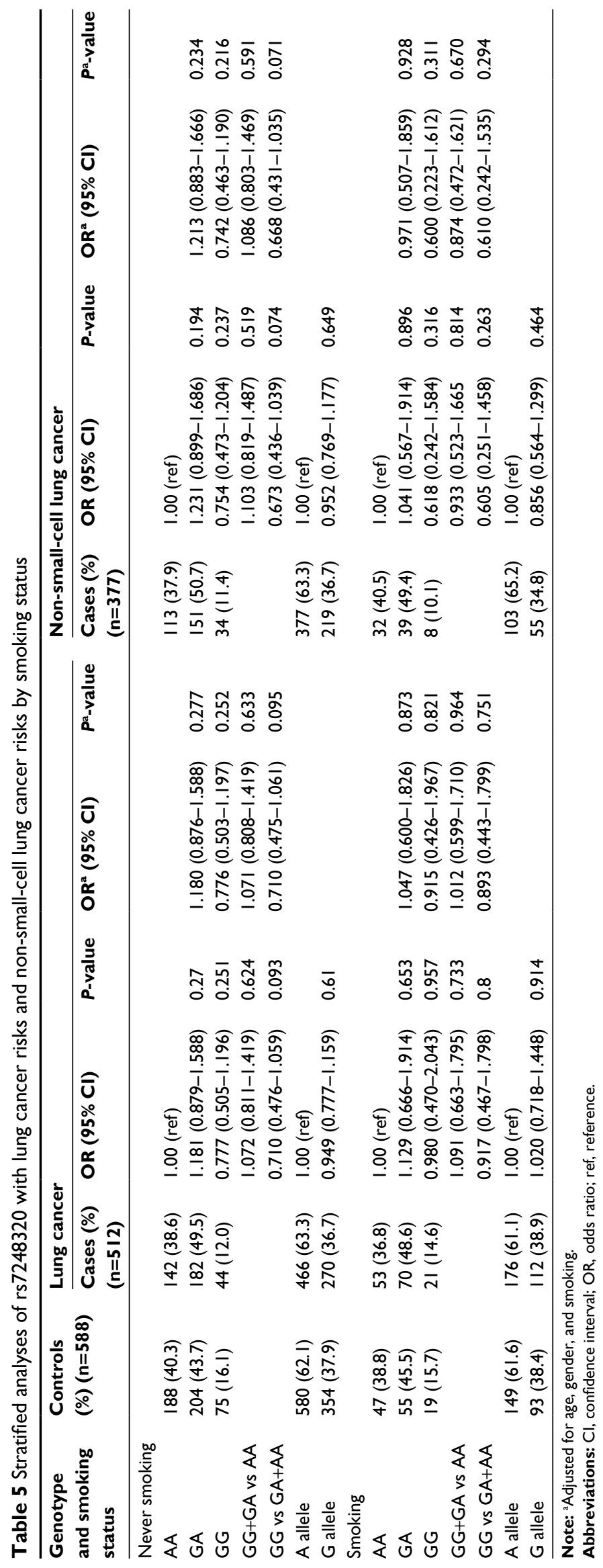




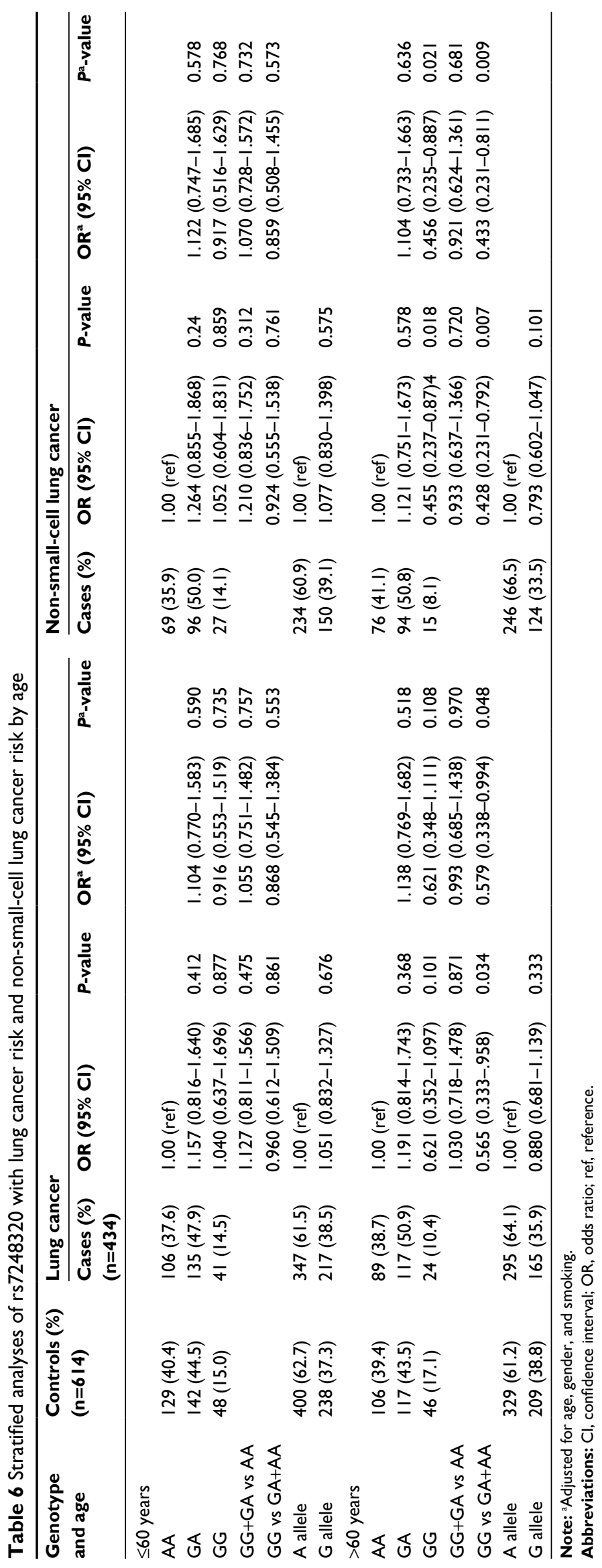


Table 7 Relationship of interaction between rs7248320 and smoking with lung cancer risk and non-small-cell lung cancer risk

\begin{tabular}{|c|c|c|c|c|c|c|c|c|}
\hline \multirow[t]{2}{*}{ Genotype } & \multirow{2}{*}{$\begin{array}{l}\text { Controls (\%) } \\
(n=588)\end{array}$} & \multirow{2}{*}{$\begin{array}{l}\text { Smoking } \\
\text { status }\end{array}$} & \multicolumn{3}{|c|}{ Lung Cancer } & \multicolumn{3}{|c|}{ Non-small cell lung cancer } \\
\hline & & & $\begin{array}{l}\text { Cases }(\%) \\
(n=5 \mid 2)\end{array}$ & $\mathrm{OR}^{\mathrm{a}}(95 \% \mathrm{Cl})$ & $P^{a}$-value & $\begin{array}{l}\text { Cases }(\%) \\
(n=377)\end{array}$ & $\mathrm{OR}^{\mathrm{a}}(95 \% \mathrm{Cl})$ & $P^{a}$-value \\
\hline GG & $75(12.8)$ & Never & $44(8.6)$ & 1.00 (ref) & & $34(9.0)$ & $\mathrm{I} .00$ (ref) & \\
\hline $\mathrm{GA}+\mathrm{AA}$ & $392(66.7)$ & Never & $324(63.3)$ & $\mathrm{I} .420(0.95 \mathrm{I}-2.12 \mathrm{I})$ & 0.086 & $264(70.0)$ & $1.499(0.969-2.319)$ & 0.069 \\
\hline GG & $19(3.2)$ & Ever & $21(4.1)$ & $2.110(0.998-4.459)$ & 0.050 & $8(2.1)$ & $1.176(0.457-3.026)$ & 0.736 \\
\hline $\mathrm{GA}+\mathrm{AA}$ & $102(17.3)$ & Ever & $123(24)$ & $2.319(1.416-3.798)$ & 0.001 & 71 (18.8) & $1.963(1.134-3.399)$ & 0.016 \\
\hline
\end{tabular}

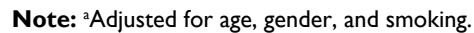

Abbreviations: $\mathrm{Cl}$, confidence interval; OR, odds ratio; ref, reference.

Table 8 Relationship of interaction between rs7248320 and smoking with lung adenocarcinoma risk and lung squamous cell carcinoma risk

\begin{tabular}{|c|c|c|c|c|c|c|c|c|}
\hline \multirow[t]{2}{*}{ Genotype } & \multirow{2}{*}{$\begin{array}{l}\text { Controls (\%) } \\
(n=588)\end{array}$} & \multirow{2}{*}{$\begin{array}{l}\text { Smoking } \\
\text { status }\end{array}$} & \multicolumn{3}{|c|}{ Lung adenocarcinoma } & \multicolumn{3}{|c|}{ Lung squamous cell carcinoma } \\
\hline & & & $\begin{array}{l}\text { Cases }(\%) \\
(n=258)\end{array}$ & OR $^{a}(95 \% \mathrm{CI})$ & $P^{a}$-value & $\begin{array}{l}\text { Cases (\%) } \\
(n=\mid 10)\end{array}$ & OR $^{a}(95 \% \mathrm{Cl})$ & $P^{a}$-value \\
\hline GG & $75(12.8)$ & Never & $28(10.9)$ & $\mathrm{I} .00$ (ref) & & $6(5.5)$ & $\mathrm{I} .00$ (ref) & \\
\hline $\mathrm{GA}+\mathrm{AA}$ & $392(66.7)$ & Never & $203(78.7)$ & I.377 (0.860-2.204) & 0.182 & $55(50.0)$ & $1.810(0.749-4.375)$ & 0.188 \\
\hline GG & $19(3.2)$ & Ever & $4(1.6)$ & $0.863(0.26 \mathrm{I}-2.849)$ & 0.809 & $4(3.6)$ & $2.369(0.591-9.502)$ & 0.224 \\
\hline $\mathrm{GA}+\mathrm{AA}$ & $102(17.3)$ & Ever & $23(8.9)$ & $0.970(0.496-1.896)$ & 0.928 & $45(40.9)$ & $4.846(1.892-12.416)$ & 0.001 \\
\hline
\end{tabular}

Note: adjusted for age, gender, and smoking.

Abbreviations: $\mathrm{Cl}$, confidence interval; OR, odds ratio; ref, reference.

AA/GA genotypes. Similarly, they also found that rs 7248320 GG genotype increased the cervical cancer risk by 1.34 -fold (95\% CI $=1.09-1.66, P=0.006)$. In the past studies, they found that rs $7248320 \mathrm{GG}$ genotype was a risk factor for HCC and cervical cancer.

Perhaps the pathogenic mechanisms were diverse in different cancers; hence, the effects of rs $7248320 \mathrm{GG}$ genotype were different. We found that rs $7248320 \mathrm{GG}$ genotype could be a protecting factor in NSCLC. In this ongoing case-control study, we evaluated the association between rs 7248320 polymorphism in lncRNA AC008392.1 and the susceptibility of lung cancer in a Chinese population of 512 lung cancer cases and 588 cancer-free controls. To our knowledge, this is the first study to investigate the relationship between rs 7248320 and lung cancer risk. The results of our study suggest that the rs7248320GG genotype for IncRNA AC008392.1 compared with GA/AA genotypes was associated with deceased risk of NSCLC (adjusted $P=0.033$ ). Moreover, in the subgroup of ages, individuals with GG genotype had a lower risk on lung cancer or NSCLC compared with individuals with GA/ AA genotypes (adjusted $P=0.048$ or $P=0.009$, respectively). The homogeny GG could play an important role in reducing the susceptibility of NSCLC (adjusted $P=0.021$ ). This study may help to identify people who are more susceptible to NSCLC. Individuals with dangerous genotypes should pay more attention to the occurrence and development of NSCLC. However, we failed to find the statistically significant association between rs7248320 and SQ. The same results were also found in AD group. NSCLC includes large cell lung cancer, $\mathrm{AD}, \mathrm{SQ}$, and so on. SQ, mostly originated from the larger bronchi, is often central lung cancer, and $\mathrm{AD}$ is mostly peripheral lung cancer. The sample size in the present study may be too small to get significant results in $\mathrm{AD}$ and SQ. The same problem also exists in the subgroup analysis.

Few studies investigated the function of gene-environment interaction on the risk of lung cancer. Therefore, in the case-control study, we investigated the interaction between exposure to smoking status and the SNP rs7248320 on lung cancer risk. The crossover analysis in this study qualitatively suggests the meaningful interaction between rs 7248320 and smoking exposure on the susceptibility of lung cancer, NSCLC, and SQ in Chinese population. Then, the quantitative analyses in this study have shown that the interaction between this SNP rs7248320 and smoking status exposure did not have any statistical significance on an additive scale. These results might be due to the small sample size.

Several limitations should be noted in the present casecontrol study. First, the study is based on the hospital from which the cases and controls were selected, which might lead to Berkson's bias. In order to reduce the Berkson's bias, we chose the cases and controls from several different hospitals in Shenyang. Second, we collected the data of smoking exposure in participants which may result in recall bias. Third, the sample size in the present study may be too small 
to get significant results; hence, the relationship between the SNP rs 7248320 in lncRNA AC008392.1 and lung cancer risk need to be validated by further large size studies. Finally, we did not experiment to determine whether the association between the genotypes of rs 7248320 and the expression of the lncRNA AC008392.1 existed. However, the study reported that LncRNA AC008392.1 rs7248320 may represent the eQTL for CARD8 by bioinformatics analyses. It has been shown that there is a significant association between the genotypes of eQTL SNP and the expression of the corresponding lncRNA. ${ }^{55}$ Hence, further studies are needed.

\section{Conclusion}

In this study, we found the association between rs 7248320 A $>$ G polymorphism in IncRNA AC008392.1 and the susceptibility to lung cancer in Chinese population. The interactions between rs 7248320 and smoking exposure were not statistically significant.

\section{Acknowledgment}

This study was supported by the National Natural Science Foundation of China (number 81673261).

\section{Disclosure}

The authors report no conflicts of interest in this work.

\section{References}

1. Jemal A, Bray F, Center MM, Ferlay J, Ward E, Forman D. Global cancer statistics. CA Cancer J Clin. 2011;61(2):69-90.

2. Oak CH, Wilson D, Lee HJ, Lim HJ, Park EK. Potential molecular approaches for the early diagnosis of lung cancer (review). Mol Med Rep. 2012;6(5):931-936.

3. Yin Z, Cui Z, Li H, et al. Polymorphisms in miR-135a-2, miR-219-2 and miR-211 as well as their interaction with cooking oil fume exposure on the risk of lung cancer in Chinese nonsmoking females: a case-control study. BMC Cancer. 2016;16(1):751.

4. Yin Z, Cui Z, Ren Y, et al. Association between polymorphisms in pre-miRNA genes and risk of lung cancer in a Chinese non-smoking female population. Lung Cancer. 2016;94:15-21.

5. ENCODE Project Consortium. An integrated encyclopedia of DNA elements in the human genome. Nature. 2012;489(7414):57-74.

6. Lowe CB, Haussler D. 29 mammalian genomes reveal novel exaptations of mobile elements for likely regulatory functions in the human genome. PLoS One. 2012;7(8):e43128.

7. Bernstein BE, Stamatoyannopoulos JA, Costello JF, et al. The NIH Roadmap Epigenomics Mapping Consortium. Nat Biotechnol. 2010;28(10): 1045-1048.

8. Li H, Lv X. Functional annotation of noncoding variants and prioritization of cancer-associated lncRNAs in lung cancer. Oncol Lett. 2016;12(1):222-230.

9. Lv Z, Xu Q, Yuan Y. A systematic review and meta-analysis of the association between long non-coding RNA polymorphisms and cancer risk. Mutat Res. 2017;771:1-14.

10. Birney E, Stamatoyannopoulos JA, Dutta A, et al. Identification and analysis of functional elements in $1 \%$ of the human genome by the ENCODE pilot project. Nature. 2007;447(7146):799-816. 
11. Esteller M. Non-coding RNAs in human disease. Nat Rev Genet. 2011;12(12):861-874.

12. Li H, Ren Y, Xia L, et al. Association of microRNA-149 polymorphism with lung cancer risk in chinese non-smoking female: a case-control study. PLoS One. 2016;11(9):e0163626.

13. Zhang J, LiY, Dong M, Wu D. Long non-coding RNA NEAT1 regulates E2F3 expression by competitively binding to miR-377 in non-small cell lung cancer. Oncol Lett. 2017;14(4):4983-4988.

14. Barrdahl M, Canzian F, Lindstrom S, et al. Association of breast cancer risk loci with breast cancer survival. Int J Cancer. 2015;137(12):2837-2845.

15. Barzan D, Veldwijk MR, Herskind C, et al. Comparison of genetic variation of breast cancer susceptibility genes in Chinese and German populations. Eur J Hum Genet. 2013;21(11):1286-1292.

16. Liu B, Chen Y, Yang J. LncRNAs are altered in lung squamous cell carcinoma and lung adenocarcinoma. Oncotarget. 2017;8(15):24275-24291.

17. Cao DL, Gu CY, Zhu Y, et al. Polymorphisms at long non-coding RNAs and prostate cancer risk in an eastern Chinese population. Prostate Cancer Prostatic Dis. 2014;17(4):315-319.

18. Deng LL, Chi YY, Liu L, Huang NS, Wang L, Wu J. LINC00978 predicts poor prognosis in breast cancer patients. Sci Rep. 2016;6:37936.

19. Ponting CP, Oliver PL, Reik W. Evolution and functions of long noncoding RNAs. Cell. 2009;136(4):629-641.

20. Han J, Zhou W, Jia M, et al. Expression quantitative trait loci in long non-coding RNA PAX8-AS1 are associated with decreased risk of cervical cancer. Mol Genet Genomics. 2016;291(4):1743-1748.

21. Huang R, Wang X, Zhang W, et al. Down-regulation of lncRNA DGCR5 correlates with poor prognosis in hepatocellular carcinoma. Cell Physiol Biochem. 2016;40(3-4):707-715.

22. Johnson R. Long non-coding RNAs in Huntington's disease neurodegeneration. Neurobiol Dis. 2012;46(2):245-254.

23. Yang Q, Xu E, Dai J, et al. A novel long noncoding RNA AK001796 acts as an oncogene and is involved in cell growth inhibition by resveratrol in lung cancer. Toxicol Appl Pharmacol. 2015;285(2):79-88.

24. Zhan Y, Li Y, Guan B, et al. Long non-coding RNA HNF1A-AS1 promotes proliferation and suppresses apoptosis of bladder cancer cells through upregulating Bcl-2. Oncotarget. 2017;8(44):76656-76665.

25. Barter MJ, Gomez R, Hyatt S, et al. Long noncoding RNA ROCR contributes to SOX9 expression and chondrogenic differentiation of human mesenchymal stem cells. Development. 2017;144(24):4510-4521.

26. Li P, Zhang G, Li J, et al. Long noncoding RNA RGMB-AS1 indicates a poor prognosis and modulates cell proliferation, migration and invasion in lung adenocarcinoma. PLoS One. 2016;11(3): e0150790.

27. Quan M, Chen J, Zhang D. Exploring the secrets of long noncoding RNAs. Int J Mol Sci. 2015;16(3):5467-5496.

28. Zhai N, Xia Y, Yin R, Liu J, Gao F. A negative regulation loop of long noncoding RNA HOTAIR and p53 in non-small-cell lung cancer. Onco Targets Ther. 2016;9:5713-5720.

29. Lin Y, Ge Y, Wang Y, et al. The association of rs 710886 in lncRNA PCAT1 with bladder cancer risk in a Chinese population. Gene. 2017;627:226-232.

30. da Silva WC, Oshiro TM, de Sa DC, Franco DD, Festa Neto C, Pontillo A. Genotyping and differential expression analysis of inflammasome genes in sporadic malignant melanoma reveal novel contribution of CARD8, IL1B and IL18 in melanoma susceptibility and progression. Cancer Genet. 2016;209(10):474-480.

31. Takahashi H, Okayama N, Yamaguchi N, et al. Associations of interactions between NLRP3 SNPs and HLA mismatch with acute and extensive chronic graft-versus-host diseases. Sci Rep. 2017;7(1):13097.

32. Checinska A, Oudejans JJ, Span SW, Rodriguez JA, Kruyt FA, Giaccone G. The expression of TUCAN, an inhibitor of apoptosis protein, in patients with advanced non-small cell lung cancer treated with chemotherapy. Anticancer Res. 2006;26(5b):3819-3824.

33. Wang H, Hua M, Wang S, et al. Genetic polymorphisms of IL-18 rs1946518 and IL-1beta rs16944 are associated with prognosis and survival of acute myeloid leukemia. Inflamm Res. 2017;66(3):249-258.

34. Stein JP, Lieskovsky G, Cote R, et al. Radical cystectomy in the treatment of invasive bladder cancer: long-term results in 1,054 patients. J Clin Oncol. 2001;19(3):666-675.
35. Yi M, Shao X, Ma J, Tian B, Zhang Y, Liu S. rs2043211 polymorphism in CARD8 is not associated with Tourette syndrome in a family-based association study in the Chinese Han population. Int J Psychiatry Med. 2015;49(3):208-214.

36. Xia R, Sheng X, Xu X, Yu C, Lu H. Hesperidin induces apoptosis and $\mathrm{G} 0 / \mathrm{G} 1$ arrest in human non-small cell lung cancer A549 cells. Int J Mol Med. 2018;41(1):464-472.

37. Pathan N, Marusawa H, Krajewska M, et al. TUCAN, an antiapoptotic caspase-associated recruitment domain family protein overexpressed in cancer. J Biol Chem. 2001;276(34):32220-32229.

38. Krajewska M, Kim H, Kim C, et al. Analysis of apoptosis protein expression in early-stage colorectal cancer suggests opportunities for new prognostic biomarkers. Clin Cancer Res. 2005;11(15):5451-5461.

39. Checinska A, Giaccone G, Hoogeland BS, Ferreira CG, Rodriguez JA, Kruyt FA. TUCAN/CARDINAL/CARD8 and apoptosis resistance in non-small cell lung cancer cells. BMC Cancer. 2006;6:166.

40. He ML, Chen Y, Chen Q, et al. Multiple gene dysfunctions lead to high cancer-susceptibility: evidences from a whole-exome sequencing study. Am J Cancer Res. 2011;1(4):562-573.

41. Yin J, Wen J, Hang D, et al. Expression quantitative trait loci for CARD8 contributes to risk of two infection-related cancers - hepatocellular carcinoma and cervical cancer. PLoS One. 2015;10(7):e0132352.

42. Boyle AP, Hong EL, Hariharan M, et al. Annotation of functional variation in personal genomes using RegulomeDB. Genome Res. 2012;22(9):1790-1797.

43. Yin Z, Li H, Cui Z, et al. Polymorphisms in pre-miRNA genes and cooking oil fume exposure as well as their interaction on the risk of lung cancer in a Chinese nonsmoking female population. Onco Targets Ther. 2016;9:395-401.

44. Jen J, Tang YA, Lu YH, Lin CC, Lai WW, Wang YC. Oct4 transcriptionally regulates the expression of long non-coding RNAs NEAT1 and MALAT1 to promote lung cancer progression. Mol Cancer. 2017;16(1): 104 .

45. Gutschner T, Baas M, Diederichs S. Noncoding RNA gene silencing through genomic integration of RNA destabilizing elements using zinc finger nucleases. Genome Res. 2011;21(11):1944-1954.

46. Zhu H, Lv Z, An C, et al. Onco-lncRNA HOTAIR and its functional genetic variants in papillary thyroid carcinoma. Sci Rep. 2016;6:31969.

47. Peng Z, Zhang C, Duan C. Functions and mechanisms of long noncoding RNAs in lung cancer. Onco Targets Ther. 2016;9:4411-4424.

48. Zhou Y, Sheng B, Xia Q, Guan X, Zhang Y. Association of long noncoding RNA H19 and microRNA-21 expression with the biological features and prognosis of non-small cell lung cancer. Cancer Gene Ther. 2017;24(8):317-324.

49. Schmidt LH, Spieker T, Koschmieder S, et al. The long noncoding MALAT-1 RNA indicates a poor prognosis in non-small cell lung cancer and induces migration and tumor growth. $J$ Thorac Oncol. 2011;6(12):1984-1992.

50. Gutschner T, Hammerle M, Eissmann M, et al. The noncoding RNA MALAT1 is a critical regulator of the metastasis phenotype of lung cancer cells. Cancer Res. 2013;73(3):1180-1189.

51. Liu W, Yin NC, Liu H, Nan KJ. Cav-1 promote lung cancer cell proliferation and invasion through lncRNA HOTAIR. Gene. 2018;641:335-340.

52. Hou Z, Zhao W, Zhou J, et al. A long noncoding RNA Sox2ot regulates lung cancer cell proliferation and is a prognostic indicator of poor survival. Int J Biochem Cell Biol. 2014;53:380-388.

53. Yamamoto M, Torigoe T, Kamiguchi K, et al. A novel isoform of TUCAN is overexpressed in human cancer tissues and suppresses both caspase-8- and caspase-9-mediated apoptosis. Cancer Res. 2005;65(19):8706-8714.

54. Bouchier-Hayes L, Conroy H, Egan H, et al. CARDINAL, a novel caspase recruitment domain protein, is an inhibitor of multiple NF-kappa B activation pathways. $J$ Biol Chem. 2001;276(47):44069-44077.

55. Wen J, Liu Y, Liu J, et al. Expression quantitative trait loci in long noncoding RNA ZNRD1-AS1 influence both HBV infection and hepatocellular carcinoma development. Mol Carcinog. 2015;54(11):1275-1282. 
Cancer Management and Research

\section{Publish your work in this journal}

Cancer Management and Research is an international, peer-reviewed open access journal focusing on cancer research and the optimal use of preventative and integrated treatment interventions to achieve improved outcomes, enhanced survival and quality of life for the cancer patient.

The manuscript management system is completely online and includes

Submit your manuscript here: https://www.dovepress.com/cancer-management-and-research-journal

a very quick and fair peer-review system, which is all easy to use. Visit $\mathrm{http}: / / \mathrm{www}$.dovepress.com/testimonials.php to read real quotes from published authors. 